\title{
Thermal Management of Lithium/Sulphur Cells Using a Simple 2D Model
}

\author{
Desmond Adair $^{1}$, Kairat Ismailov ${ }^{1}$, Yerzhan Massalin ${ }^{1,2}$, and Zhumabay Bakenov ${ }^{1,2}$ \\ 1. Nazarbayev University, Republic of Kazakhstan \\ 2. Institute of Batteries, Republic of Kazakhstan
}

\begin{abstract}
Lithium sulphur (Li/S) batteries are currently receiving significant attention as an alternative power source for zero-emission vehicles and advanced electronic devices due to the very high theoretical specific capacity of the sulphur cathode. Here a simple 2D transient method for the simulation of thermal characteristics of a lithium/sulfur cell is developed. The method is capable of determining the transient response of the thermal field. The heat sources associated with charging and discharging are estimated from experimental data and used as boundary conditions, and the simulations are performed at different charge and discharge current rates. The simulations were carried out for natural cooling.
\end{abstract}

Key words: lithium-ion battery, lithium/sulphur cells, natural cooling

\section{Introduction}

Air pollution and environmental concerns has spurred world-wide interest in the development of advanced batteries for electric vehicle application. Lithium-ion batteries (LIBs) are the state-of-the-art power sources for electric vehicles such as Hybrid Electric Vehicles (HEVs), Battery Electric Vehicles (BEVs) and Plug-in Hybrid Electric Vehicles (PHEVs) and the most promising energy storage systems for renewable energy and its integration into grids. LIBs combine excellent cycle life, no memory effect and high energy density and power.

However during battery cycling, exothermic electrochemical reactions occur generating heat which accumulates inside the battery and negatively affects the battery performance by accelerating its degradation. As the charge/discharge current rates increase, heat generation within the battery also increases and if cooling is insufficient the battery

Corresponding author: Desmond Adair, Ph.D., Associate Professor, research area/interests: numerical analysis. E-mail: d.adair@nu.edu.kz. temperature can rise significantly and even cause thermal run-away [1]. This would be especially true for large-scale batteries, and if the battery is operated in a hot environment or under insulating conditions. It is also important to lithium batteries to operate within a certain temperature range and to have an equal temperature distribution/dissipation throughout each cell.

In a battery thermal management system, it is desirable to accurately predict the internal temperature evolution of the battery according to the state-of-charge (SOC), cell potential, current and surface temperature [2]. Such a system requires an efficient thermal model with a limited number of measured parameters at each state. Therefore heat dissipation in a cell must be properly studied in order to avoid elevated temperatures where decomposition reactions of the electrodes and electrolyte might start [3]. A number of models have already been developed to study the thermal behavior of Li-ion or Li-polymer batteries with theoretical models [4-6] based on electrochemistry and physics giving accurate predictions but are complicated and need sophisticated 
measurements and estimation of transport properties, electrochemical constants, etc. to be accurately solved.

This paper presents the development of a simple thermal model for a lithium sulphur cell which is then used to investigate the cell temperature distribution over the battery surface at different current rates and ambient temperatures

\section{Mathematical Model}

It is assumed that the lithium/sulphur cells have a small thickness, so in this model heat distributions are only calculated in two planar directions. The battery is made of three distinct computational domains, i.e., the electrodes, the casing (cold housing), and the tabs as shown on Fig. 1.

Convection is very small within a battery cell and can be ignored [7], leaving just the diffusion terms, the transient term plus a heat source in the heat conduction equation in the electrode domain, i.e.,

$$
\rho c_{p} \frac{\theta}{\partial t}=\nabla \cdot \lambda \nabla \theta+\dot{q},
$$

where $\theta$ is the temperature, $q$ is the volumetric heat generation and $\rho, c_{p}$ and $\lambda$ are the area averaged density, specific heat and heat conductivity of the electrodes.

The heat generation rate depends on the thermodynamic properties of the reactions involved in a cell, the potential-current characteristics of the cell, and the rates of charge and discharge. By utilizing the first law of thermodynamics for an isobaric battery

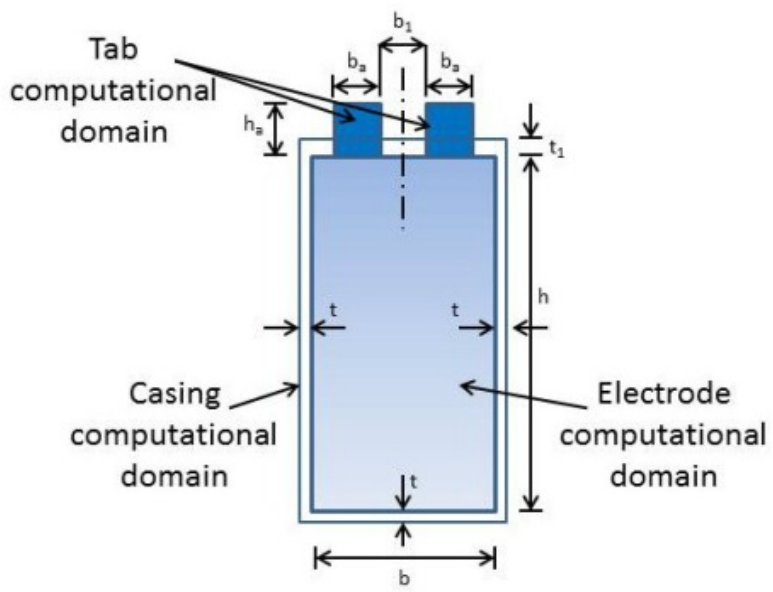

Fig. 1 Schematic diagram of the lithium sulphur cell. system, Bernardi et al. [8] gave a general energy balance equation for a cell in which the rate of heat generation can be simplified to

$$
\begin{aligned}
\dot{q}=\dot{q}_{\text {joule }}+\dot{q}_{\text {reaction }} & =\frac{1}{V}\left(\left(U_{0}-U\right)-\theta \frac{d U_{0}}{d \theta}\right) \\
& =\frac{I}{V}\left(R I-\left(\theta \frac{d U_{0}}{d \theta}\right)\right)
\end{aligned}
$$

where $I$ is the current, $V$ is the cell voltage, $R$ is the internal resistance, $U_{0}$ is the open-circuit potential, $U$ is the working voltage and $d U_{0} / d \theta$ is the temperature coefficient of voltage. The terms in the original expression [8], namely the "enthalpy of mixing" and "phase change", were both set to zero, i.e., it was assumed that concentration gradients developed within the cell were either zero or negligible and no phase changes occurred.

The term $\left(\theta\left(d U_{0} / d \theta\right) I\right)$ on the r.h.s. of (2), can be positive or negative depending on the sign of the current (positive in charge and negative in discharge) and also on the sign of the temperature coefficient of voltage. The temperature coefficient of voltage varies both with temperature and state-of-charge (SoC) and this parameter was measured during a $1 \mathrm{C}$ rate discharge with results shown on Fig. 2. The measurements were fitted using a sixth-order polynomial, and the correlation coefficient was $99.7 \%$.

The internal electric resistance $R$ also varies with SOC and with temperature. This parameter was measured during the $1 \mathrm{C}$ rate of discharge with the results shown on Fig. 3. The internal electric resistance decreases until $60 \%$ SOC, and then increases, especially at the end of the discharge.

The density heat flux from the battery surface is composed of two components, the convection heat transfer (natural or forced convection) and radiation heat transfer. The convective and radiative heat dissipation rate are evaluated from

$$
\begin{aligned}
& \dot{q}_{\text {convection }}=h\left(\theta_{s}-\theta_{a}\right) \\
& \dot{q}_{\text {radiation }}=\varepsilon \sigma\left(\theta_{s}^{4}-\theta_{a}^{4}\right)
\end{aligned}
$$

where, $h$ is the convection heat transfer coefficient, 


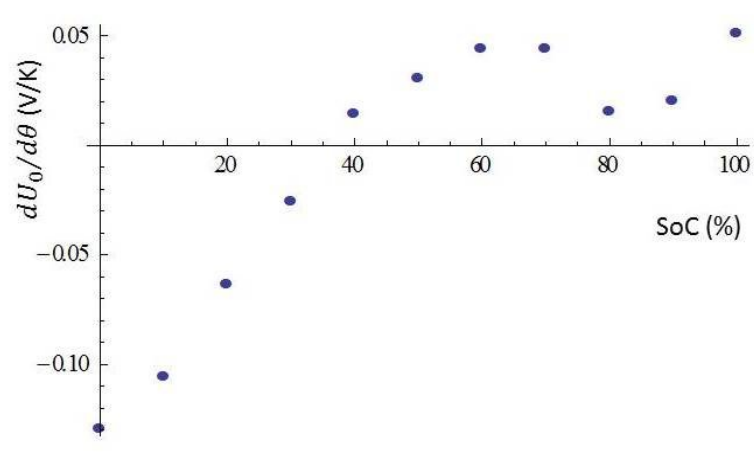

Fig. 2 The temperature coefficient of voltage as a function of state of charge (SoC) during $1 \mathrm{C}$ rate of discharge.

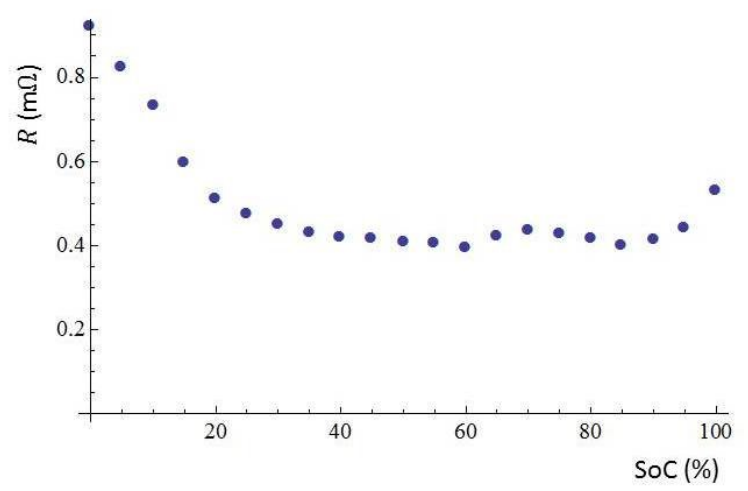

Fig. 3 The internal electric resistance during $1 \mathrm{C}$ rate of discharge.

$\sigma$ is the Stefan-Boltzmann constant, $\varepsilon$ is the emissivity of the cell surface, and subscripts $s$ and $a$ refer to cell surface and ambient respectively.

When natural convection is involved, the Rayleigh number controls the flow regime [9], with the Rayleigh number defined as

$$
R a=\frac{\beta_{\mathrm{air}} g\left(\theta-\theta_{a}\right) L^{3}}{v_{\text {air }}^{2}}
$$

where, $\beta_{\text {air }}$ is the coefficient of thermal expansion, $g$ is the acceleration due to gravity, $L$ is the battery length and $v_{\text {air }}$ is the kinematic viscosity. For the laminar flow regime, i.e., $10^{3}<R a<10^{9}, h=0.59 \lambda_{\text {air }} / L R a^{0.25}$ and for the turbulent flow regime, i.e., $10^{9}<R a<10^{14}$, $h=$ $0.10 \lambda_{\text {air }} / L R a^{0.33}$. Here $\lambda_{\text {air }}$ is the thermal conductivity of air.

The heat transfer and temperature rise characteristics of a battery cell are largely determined by the physical and thermal characteristics of the component materials together with the heat source. This study measured the specific heat capacity, density and thermal conductivity of the battery shell, sulphur/carbon cathode, lithium/graphite anode, ethylene carbonate/diethylene (1:1) electrolyte and propylene separator.

The electrodes computational domain is considered here to contain the anode, separator, electrolyte, and cathode. This complicated model is reduced to a solid block with the density and heat capacity calculated based on the volume of each constituent

$$
\begin{gathered}
\rho_{\text {eff }}=\sum_{i=1}^{n}\left(\rho_{i} V_{i}\right) /\left(\sum_{i=1}^{n} V_{i}\right) \\
C_{p \text { eff }}=\frac{1}{m} \sum_{i=1}^{n} C_{p} m_{i}
\end{gathered}
$$

where, $\rho_{\text {eff }} \rho_{\text {eff }}$ and $C_{\text {peff }}$ are the effective density and specific heat of the electrodes computational domain, respectively, and, $\rho_{i}, V_{i}, m_{i}$, are the respective components of the electrodes computational domain's density, volume and mass. The total mass of the electrodes computational domain is represented by $m$.

Most of the electrodes computational area is filled with organic electrolyte and due to comparable thermal conductivity between organic, separator and the electrode, their contact thermal resistance is insignificant. The arrangement of the electrodes and separator along different directions can be characterized as in series or as in parallel [10]. As thickness is considered negligible here, the arrangement in parallel is relevant and the thermal conductivity is determined using

$$
k=\frac{\sum_{i=1}^{n} k_{i} A_{i}}{\sum_{i=1}^{n} A_{i}}
$$

where $k_{i}$ and $A_{i}$ represent the thermal conductivity and area of the respective components within the electrode computational domain.

Table 1 lists the thermal and physical properties of the component materials.

\section{Results and Discussion}

Fig. 4 shows the results of the heat distributions over the cell using the above mathematical model for 
Table 1 Thermal and physical properties of materials. Density and heat capacity were calculated using (5) and the thermal conductivity was calculated using (6).

\begin{tabular}{|l|l|l|l|}
\hline Component & $\begin{array}{l}\text { Density } \\
\left(\mathrm{kg} / \mathrm{m}^{3}\right)\end{array}$ & $\begin{array}{l}\text { Heat } \\
\text { capacity } \\
(\mathrm{J} /(\mathrm{kg} \mathrm{K})\end{array}$ & $\begin{array}{l}\text { Thermal } \\
\text { conductivity } \\
(\mathrm{W} /(\mathrm{m} \mathrm{K})\end{array}$ \\
\hline $\begin{array}{l}\text { Sulphur/carbon } \\
\text { cathode }\end{array}$ & 1355 & 1217 & 1.58 \\
\hline $\begin{array}{l}\text { Graphite/Lithium } \\
\text { anode }\end{array}$ & 2217 & 1437 & 1.05 \\
\hline Organic electrolyte & 1124 & 135.8 & 0.63 \\
\hline Separator & 1008 & 1978 & 0.42 \\
\hline Aluminum & 2702 & 903.1 & 238 \\
\hline Copper & 8933 & 385 & 398 \\
\hline Shell (ABS) & 930 & 1837 & 0.42 \\
\hline
\end{tabular}

different selected time steps during a $1 \mathrm{C}$ charge capacity test. The results are for natural convection and the ambient temperature was set at $20^{\circ} \mathrm{C}$. It can be seen that the surface temperature across the cell is fairly uniform except for the central region.

The maximum temperature difference across the cell was about $0.8^{\circ} \mathrm{C}-1.0^{\circ} \mathrm{C}$ depending on the time during the test.

The temperature increases calculated during different charge rates are shown on Fig. 5.

The temperature gain during the $1 \mathrm{C}$ charge rate was found to be $9^{\circ} \mathrm{C}$ which is capable with experimental results found for lithium cells in the literature.

Results for discharge were also found, with the temperature distributions over the cell shown on Fig. 6.

The overall temperature was higher a full discharge compared to the temperature at full charge and the temperature difference across the cell reached nearly $2.5^{\circ} \mathrm{C}$. The hottest region is seen to be towards the
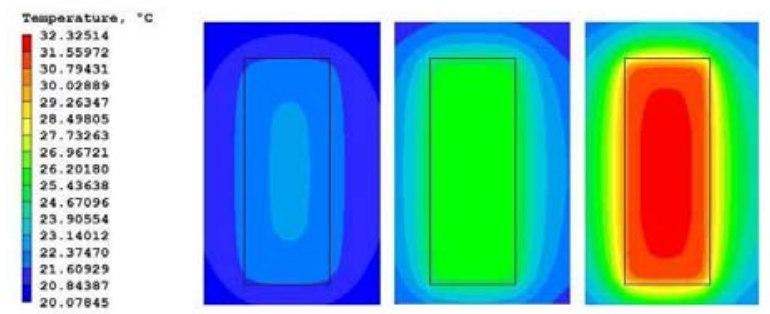

(a) $t=20$ min (b) $t=60$ min (c) Fully charged

Fig. 4 Temperature distributions obtained at $1 \mathrm{C}$ charge current rate.

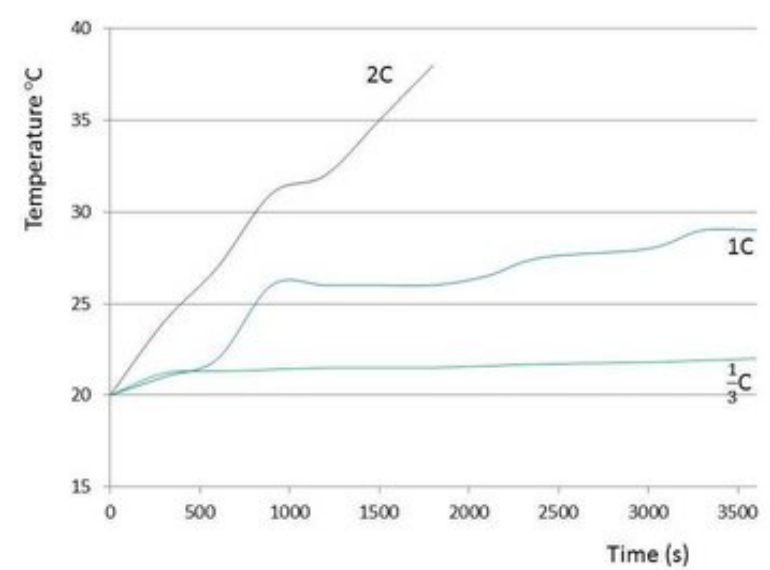

Fig. 5 Temperature distributions during different charge rates.
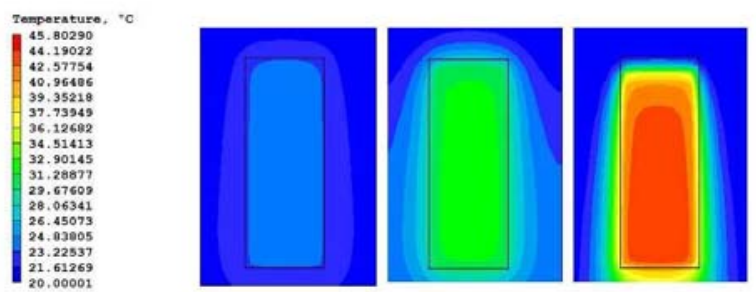

$\begin{array}{lll}\text { (a) } t=30 \min & \text { (b) } t=80 \text { min } & \text { (c) Fully discharged }\end{array}$

Fig. 6 Temperature distributions obtained at 1 C discharge current rate.

centre of the cell as was the case for the charge process.

The temperature rise for $2 \mathrm{C}$ and $1 \mathrm{C}$ current discharges is shown on Fig. 7. For the $1 \mathrm{C}$ a total temperature difference was found of $15.5^{\circ} \mathrm{C}$ and for the $2 \mathrm{C}$ case a total temperature difference of $20^{\circ} \mathrm{C}$.

In electric vehicles batteries are subjected to heavy demands due to say fast charging and rapid acceleration.

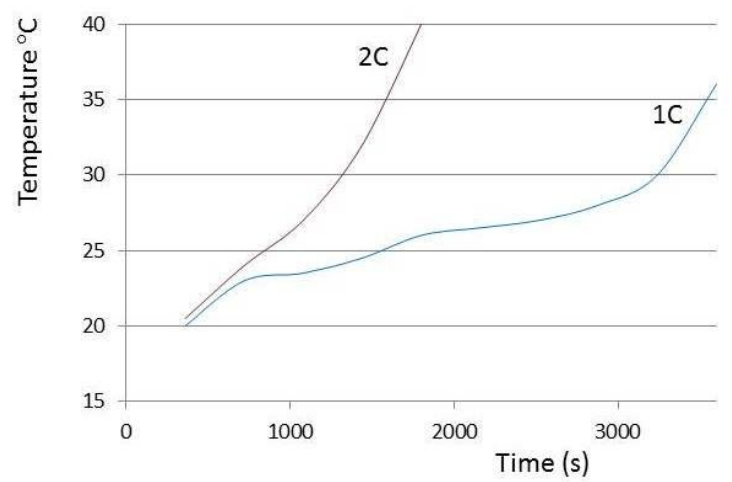

Fig. 7 Temperature distributions during different discharge current rates. 


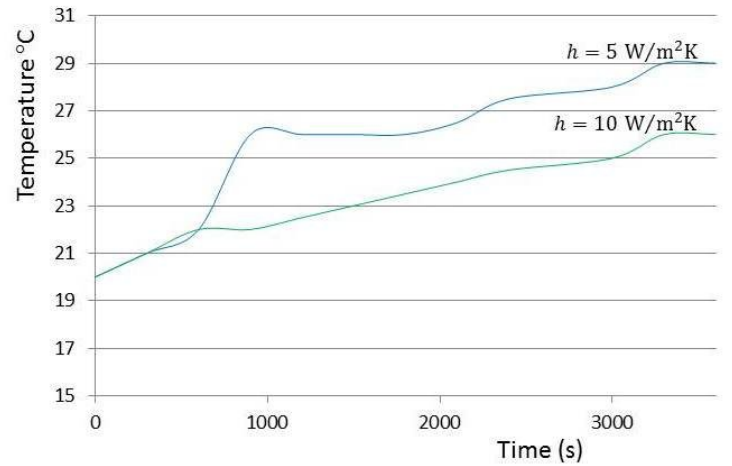

Fig. 8 Surface temperatures for different heat transfer coefficients at $1 \mathrm{C}$.

The link between a suitable cooling system to combat the subsequent rises in temperature, and the cell, is through the heat transfer coefficient $(h)$. The effect of varying $h$ is shown on Fig. 8 when there is natural convection and for the $1 \mathrm{C}$ case for values of 5 and 10 $\mathrm{W} / \mathrm{m}^{2} \mathrm{~K}$. The difference in maximum rise in temperature was found to be approximately $10^{\circ} \mathrm{C}$.

\section{Conclusions}

A simple 2D mathematical model capable of predicting the thermal distribution across a lithium sulphur battery has been developed. The temperature distributions were found to be fairly uniform with the discharge process final temperature larger than that found during the charge process. The value of heat transfer coefficient is shown to be critical to any cooling strategy of the cell.

\section{Acknowledgements}

This research is supported by a Research Grant from the Ministry of Education and Science of Kazakhstan and by a sub-project supported under the Technology Commercialization Project by the World Bank and the Government of Kazakhstan.

\section{References}

[1] Q. Wang, P. Ping, X. Zhao, G. Chu, J. Sun and C. Chen, Thermal runaway caused fire and explosion of lithium ion battery, J. of Power Sources 208 (2012) 210-224.

[2] M. J. Rad, D. L. Danilov, M. Baghalha, M. Kazemeini, and P. H. L. Notte, Thermal modelling of cylindrical LiFePO4 batteries, J. of Modern Physics 4 (2013) 1-7.

[3] P. M. Gomadam, R. E. White and J. W. Weidner, Modeling heat conduction in spiral geometries, J. of the Electrochemical Society 150 (10) (2003) A1339-A1345.

[4] G. G. Botte, V. R. Subramanian and R. E. White, Mathematical modeling of secondary lithium batteries, Electrochimical Acta 45 (2000) 2595-2609.

[5] K. E. Thomas and J. Newman, Thermal modeling of porous insertion electrodes, J. of the Electrochemical Society 150 (2003) A176-A192.

[6] K. Smith and C. Y. Wang, Power and thermal characterization of a lithium-ion battery for hybrid electric vehicles, J. of Power Sources 160 (1) (2006) 662-673.

[7] W. B. Gu and C. Y. Wang, Thermal-electrochemical modeling of battery systems, J. of the Electrochemical Society 147 (8) (2000) 2910-2922.

[8] D. Bernardi, E. Pawlikowski and J. Newman, A general energy balance for battery systems, J. of Electrochemical Society 132 (1) (1985) 5-12.

[9] E. R. G. Eckert and R. J. Goldstein, Measurements in Heat Transfer (2nd ed.), Hemisphere Publishing Corporation, Bristol, PA, 1976.

[10] S. C. Chen, C. C. Wan and J. Wang, Thermal analysis of lithium-ion batteries, J. of Power Sources 140 (2005) 111-124. 